\title{
SER PROFESSOR NA EDUCAÇÃO INFANTIL: GÊNERO E DOCÊNCIA
}

\author{
SER PROFESOR EN LA EDUCACIÓN INFANTIL: GÉNERO Y DOCENCIA
}

BE A TEACHER IN CHILD EDUCATION: GENDER AND TEACHING

\author{
Fernanda Ferrari Ruis SCIOTTI ${ }^{1}$ \\ Marcia Cristina Argenti PEREZ ${ }^{2}$ \\ Luciana Ponce BELLIDO ${ }^{3}$
}

RESUMO: O presente trabalho tem como objetivo apresentar a trajetória de vida e profissional de um professor da Educação Infantil, bem como algumas questões de gênero envolvendo a docência. A pesquisa ocorreu em uma pré-escola municipal. Para a coleta de dados foram utilizadas as estratégias de investigação de abordagem qualitativa, como a observação participante e a realização de entrevista semiestruturada. Apreendemos momentos de interação do professor com a sua turma de alunos e alunas e suas práticas cotidianas. Através de seus relatos, o docente revelou como foi o seu ingresso na profissão, os desafios e os entraves enfrentados. Concluímos que a entrada de professores homens nesta etapa da educação pode contribuir para desconstruir concepções naturalizadas acerca da profissão, bem como romper com a imagem da mulher como educadora de crianças pequenas.

PALAVRAS-CHAVE: Gênero. Docência. Educação infantil.

RESUMEN: El presente trabajo tiene como objetivo presentar la trayectoria de vida y profesional de un profesor de Educación Infantil, así como algunas cuestiones de género que involucran la docencia. La investigación ocurrió en una pre-escuela municipal. Para la recolección de datos se utilizaron las estrategias de investigación de abordaje cualitativo como la observación participante y la realización de entrevista semiestructurada. Apreciamos momentos de interacción del profesor con su clase de alumnos y alumnas y sus prácticas cotidianas. A través de sus relatos, el docente reveló cómo fue su ingreso en la profesión, los desafios y los obstáculos enfrentados. Concluimos que la entrada de profesores hombres en esta etapa de la educación puede contribuir a desconstruir concepciones naturalizadas acerca de la profesión, así como romper con la imagen de la mujer como educadora de niños pequeños.

PALABRAS CLAVE: Género. Docencia. Educación infantil

${ }^{1}$ Universidade Estadual Paulista (UNESP), Araraquara - SP - Brasil. Programa de Pós Graduação em Educação Sexual, GEPIFE - grupo de estudos e pesquisas sobre infância, família e escolarização. UNESP/CNPQ. ORCID: $<$ http://orcid.org/0000-0003-1903-5388>. E-mail: ferferrariruis@ gmail.com

${ }^{2}$ Universidade Estadual Paulista (UNESP), Araraquara - SP - Brasil. Programa de Pós Graduação em Educação Sexual, GEPIFE - grupo de estudos e pesquisas sobre infância, família e escolarização. UNESP/CNPQ. ORCID: $<$ http://orcid.org/0000-0002-4173-9923>. E-mail: marciacap@ fclar.unesp.br

${ }^{3}$ Universidade Federal de Goiás (UFG), Goiânia - GO - Brasil. GEPIFE - grupo de estudos e pesquisas sobre infância, família e escolarização. UNESP/CNPQ. ORCID: <http://orcid.org/0000-0001-6888-9940>. E-mail: lucianaponce@ufg.com.br

RIAEE - Revista Ibero-Americana de Estudos em Educação, Araraquara, v. 14, n. esp. 2, p. 1569-1579, jul., 2019. E-ISSN: 1982-5587. DOI: $10.21723 /$ riaee.v14iesp.2.12616 
ABSTRACT: The present work has as objective to present the life and professional trajectory of a teacher of the Infantile Education, as well as some questions of gender involving the teaching. The research took place in a municipal pre-school. For the data collection qualitative research strategies were used such as participant observation and semi-structured interview. We apprehend moments of interaction of the teacher with his class of students and their daily practices. Through his stories, the teacher revealed how he was entering the profession, the challenges and the obstacles faced. We conclude that the entry of male teachers at this stage of education can contribute to deconstruct naturalized conceptions about the profession, as well as breaking with the image of the woman as educator of small children.

KEYWORDS: Gender. Teaching. Early childhood education.

\section{Introdução}

Nosso objetivo no presente trabalho consistiu em investigar a entrada de um professor homem no contexto da Educação Infantil e as concepções e questões de gênero envolvendo a docência. Para tanto, pesquisamos a sua trajetória de vida, a sua formação profissional e suas experiências docentes. Além disso, procuramos averiguar como organiza a sua prática e como interage com os meninos e as meninas que compõem a sua turma.

As relações de gênero estão presentes no meio escolar a todo o momento, sendo observadas na expectativa que essa instituição social manifesta no que diz respeito aos desempenhos, atitudes, modos de agir e às condutas de seus alunos e alunas, uma vez que se espera que apresentem comportamentos distintos.

Conforme Louro (1997, p. 89, destaques no original), "o que fica evidente, sem dúvida, é que a escola é atravessada pelos gêneros; é impossível pensar sobre a instituição sem que se lance mão das reflexões sobre as construções sociais e culturais de masculino e feminino".

Neste sentido, na concepção dessa estudiosa, todo o contexto escolar, desde a arquitetura, símbolos, disposições sobre comportamentos e práticas, estratégias de ensino e avaliação, atua na constituição de homens e mulheres, de meninos e meninas, tanto dentro quanto fora da escola, uma vez que esta instituição atinge quem dela participa ou não, especialmente, docentes e estudantes. A autora pontua que para construir e proporcionar aos diferentes sujeitos o sentido de pertencer à instituição, a escola os distingue dos que estão além de seus muros. E complementa que a escola atua também internamente, distinguindo seus sujeitos uns dos outros. Desse modo, a escola está voltada não apenas para as meninas e meninos, mas também está empenhada em disciplinar os/as responsáveis pela sua formação, ou seja, os/as professores/as (LOURO, 1997).

RIAEE - Revista Ibero-Americana de Estudos em Educação, Araraquara, v. 14, n. esp. 2, p. 1569-1579, jul., 2019. E-ISSN: $1982-5587$. 


\section{A feminização da docência}

Quando pensamos na docência, sobretudo no exercício da profissão no âmbito da Educação Infantil, espontaneamente remetemos o nosso pensamento à imagem feminina. Essa associação que se faz entre a figura da mulher enquanto educadora de crianças pequenas está vinculada a um processo de feminização do magistério, fenômeno construído historicamente e influenciado pela cultura e pelas práticas sociais.

Acerca desse processo de feminização da docência, temos na história recente que a partir da segunda metade do século XIX, no Brasil, começaram a ocorrer algumas transformações sociais que permitiram a entrada das mulheres nas salas de aula, bem como seu predomínio como professoras (LOURO, 1997; ARCE, 1997; 2001). Louro (1997) considera mais adequado compreender a maneira como se deu essa feminização ao levar em conta o processo de urbanização que estava em curso nesse período, no bojo do qual se instituía um novo estatuto de escola. Nesse momento, o crescimento da população urbana, marcado por diversos grupos sociais, como os imigrantes, vem acompanhado de novas oportunidades de trabalho, além de novas expectativas e práticas educativas e, consequentemente, o aumento da demanda por vagas na escola.

Nas décadas de 70 e 80, de acordo com Arce (2001), houve uma expressiva demanda e lutas em favor da expansão da educação pública para crianças com menos de seis anos. No entanto, a falta de uma definição por parte do Ministério da Educação (MEC) acerca dos gastos a serem destinados a essa etapa da educação e a respeito da atribuição da responsabilidade sobre a mesma, cedeu espaço para que a expansão da Educação Infantil "fosse realizada da forma mais barata possível" (ARCE, 2001, p. 177). A pesquisadora ressalta que uma das estratégias empregadas para baixar os custos consistiu na utilização do trabalho voluntário de mães.

Destarte, o magistério neste contexto se tornou "uma atividade permitida e, após muitas polêmicas, indicada para mulheres" (LOURO, 1997, p. 95, destaques no original).

O casamento e a maternidade, de acordo com Louro (1997), foram considerados como as verdadeiras carreiras das mulheres, de forma que qualquer outra profissão por elas exercida seria considerada como um desvio de tais funções sociais, a não ser que a profissão fosse ajustada aos seus atributos femininos.

Em vista disso, atuar como professora da Educação Infantil seria uma extensão do lar, das tarefas domésticas e de mãe (CARVALHO, 1995). Dessa forma, ao considerar essas atribuições como tarefa tipicamente femininas, historicamente, a Educação Infantil foi se 
constituindo enquanto um espaço composto predominantemente por mulheres. Logo, o magistério seria algo impensável para os sujeitos do sexo masculino.

Na concepção de Arce (2001), tal ambiguidade entre o científico e o doméstico pode ser percebida nos dias atuais, uma vez que no cotidiano da Educação Infantil, a utilização dos termos "tia" ou "professorinha", "configuram uma caracterização pouco definida da profissional, oscilando entre o papel doméstico de mulher/mãe e o trabalho de educar" (p. 173).

Assim, ao longo da história, a imagem do/a profissional da Educação Infantil tem sido reforçada como sendo a da mulher possuidora de "dons naturais", passiva, dócil, de modo que a sua formação profissional é deixada à margem (ARCE, 2001).

A respeito dessa naturalização tomamos com referência a concepção de Louro (1997) de que nada é natural, os indivíduos são frutos das construções sociais, de modo que o contexto e a cultura na qual estão inseridos é que ditam as atividades consideradas como masculinas e femininas. Assim, é preciso desnaturalizar essas construções, romper esses binarismos.

Em Ruis e Perez (2017, p. 285.) constata-se que:

[...] a introjeção de padrões considerados adequados a meninas e meninos por meio de normas, rotinas, usos do tempo e do espaço escolar é vista como algo natural, sendo tão pouco questionada, colaborando para que as práticas e comportamentos sexistas sejam difundidas e cristalizadas no interior das escolas.

Por conta dessa construção histórica, social e cultural, pouco se sabe a respeito dos homens que trabalham na área da educação (CARVALHO, 1998), principalmente sobre os raros professores que atuam com crianças pequenas. Desse modo, esta autora ressalta a necessidade de estudos que se dediquem à entrada de homens em profissões consideradas como femininas, como no caso dos professores da etapa inicial da educação básica.

Ruis e Perez (2017, p. 284) destacam que:

[...] a escola muitas vezes reforça os estereótipos femininos e masculinos, os quais corroboram para a perpetuação do preconceito e do sexismo. A dicotomia homem e mulher, cada vez mais presente e precoce em nossa sociedade, exerce um papel significativo no modo como as crianças são educadas.

Frente ao exposto, podemos inferir que o modo de ensinar e cuidar de crianças em idade pré-escolar pode ser compreendido como atividades socialmente construídas, ou seja, não depende de habilidades inatas, mas sim de fatores vinculados à cultura e às práticas sociais. Portanto, homens e mulheres podem aprender a ensinar e a cuidar de crianças pequenas. 


\section{Metodologia}

Para a coleta de dados foram consideradas as estratégias de investigação de abordagem qualitativa. Bogdan e Biklen (1994) defendem que a investigação qualitativa abarca a aquisição de dados descritivos, que por sua vez são obtidos por meio do contato direto do pesquisador/a com a situação estudada, dando maior ênfase ao processo do que ao produto e preocupando-se mais em aprender a perspectiva dos participantes.

Trata-se de uma abordagem que visa responder a questões particulares (MINAYO, 1994). Esse tipo de pesquisa empenha-se em “[...] trabalhar com o universo de significados, motivações, aspirações, crenças, valores e atitudes, o que corresponde a um espaço mais profundo das relações, dos processos e dos fenômenos que não podem ser reduzidos à operacionalização de variáveis [...]" (MINAYO, 1994, p. 21-22).

Assim, optamos pela observação participante e pela realização de entrevista semiestruturada. Para Lüdke e André, "ao lado da observação, a entrevista representa um dos instrumentos básicos para a coleta de dados [...]” (1986, p. 33).

A entrevista com o professor ocorreu em dois dias, nas dependências da escola. O áudio foi gravado e, posteriormente, foi realizada a sua transcrição na íntegra, obedecendo aos procedimentos éticos. Além disso, a observação participante e o registro em diários de campo foram utilizados a fim de apreender a prática do professor em sala de aula e a sua interação com a turma de alunos e alunas.

A pesquisa foi realizada em uma escola de Educação Infantil da rede municipal de ensino, localizada em uma cidade do interior paulista, na qual o professor pesquisado era o único docente do sexo masculino que atuava nesta etapa da educação.

Eduardo, o professor participante, tinha vinte e seis anos de idade e havia ingressado na carreira docente, como professor da Educação Infantil, há quatro anos. Era casado e não tinha filhos/as. Quanto a sua formação, inicialmente cursou o Magistério, em seguida formou-se em Matemática e após em Pedagogia na modalidade a distância.

Ressaltamos que ao longo do estudo todos os cuidados éticos foram tomados, de modo que a identidade do professor, bem como da instituição e do município foram mantidas em sigilo, sendo substituídas por nomes fictícios. 


\section{Tem um homem na escola: resultados e discussão}

Conforme relatado pelo professor, a sua entrada no magistério ocorreu por um acaso, de modo que o que o motivou no início foi a necessidade de uma remuneração. Até então, não tinha a pretensão de ser professor de crianças pequenas.

Ao relembrar o início de sua carreira como professor da pré-escola, o docente relatou que a sua masculinidade foi colocada à prova, não apenas pelas profissionais que já trabalhavam na escola, mas também por seus familiares, principalmente o seu pai. A sua competência enquanto professor de crianças pequenas também foi algo questionado. Ele relatou que foi muito desestimulado pela então diretora da escola a permanecer na profissão, e que foi bastante difícil vencer esse desafio.

O professor Eduardo afirmou não ter influências de seus familiares quanto à opção profissional. Em sua família não há docentes e quando começou a trabalhar na Educação Infantil conta que o seu pai chegou a brigar com ele devido aos comentários que seus colegas de trabalho faziam acerca da sua sexualidade.

Meu pai já chegou a brigar comigo por causa disso. [...] Porque no serviço já vieram falar as coisas pra ele. Aí eu cheguei e falei pro meu pai: "pai, eu estou feliz onde estou. Eu estou onde eu quero". Eu falei: "Eu não tenho que provar nada pra ninguém". Eu falei assim: “o que importa é... eu sou casado". Lógico que casamento não prova nada, mas eu não tenho que provar nada pra ninguém. Eu sei dos meus gostos. Aqui eu sou um professor. Tanto professor homem como professor mulher, ele é professor. Ele não é mais nada. Aqui a vida pessoal dele não, não cabe aqui, entendeu? $\mathrm{E}$ eu acho que tem discriminação entre homem e mulher. Tem sim (Professor Eduardo).

Em uma pesquisa realizada com educadores da Educação Infantil, Sarmento (2002) argumenta que eles também sofreram pressões familiares, sendo que alguns revelaram que seus pais se recusaram a aceitar que os filhos seguissem uma profissão considerada feminina, uma vez que haviam projetado outras profissões que na visão deles seriam masculinas.

O fato de Eduardo ter permanecido na profissão na qual o salário é irrisório e que é pouco reconhecida socialmente, rompeu em parte com o padrão estabelecido culturalmente do homem enquanto o provedor. Eduardo sentia orgulho de sua profissão e demonstrava estar satisfeito. Desse modo, a sua insistência e permanência na docência desmistifica a representação de que os homens não aderem ao magistério devido aos parcos salários (SAYÃO, 2005).

Em uma de suas falas acerca do ingresso na carreira, o professor demonstra traços da feminização do magistério como algo ainda arraigado e que permeia a sua própria concepção

RIAEE - Revista Ibero-Americana de Estudos em Educação, Araraquara, v. 14, n. esp. 2, p. 1569-1579, jul., 2019. E-ISSN: 1982-5587. 
na condição de professor de crianças pequenas, uma vez que se sente ocupando um espaço que seria feminino.

\begin{abstract}
A minha única experiência anterior foi no reforço, mas o reforço não, não acrescentou em nada pra sala de aula. E... No primeiro dia eu não podia mostrar pra crianças o que eu podia fazer. Eu... nem eu acreditava em mim naquele dia. Então agora você vê... Aqui na escola eu sempre, eu não trabalho com alunos do mini maternal e nem do maternal. Porque eles não me conhecem, então eles, querendo ou não eles acabam se assustando com... Sempre tem essas tias, né? As professoras mulheres... de repente um professor homem! Acho que eles pensam: "esse é bravo, né, esse vai ficar não sei o quê..." porque homem ele tem uma imagem assim, né? Então eu trabalhando com a minha turma, a escola toda já vai vendo o jeito que eu trabalho, então eu no próximo ano, eles já, eles já conhecem o tio Eduardo, eles já sabem como o tio Eduardo trabalha. E... Das outras escolas também. Então mesmo que seja um dia, um dia que vá substituir, então eles já acabam conhecendo. Eles sabem que o tio Eduardo não é uma pessoa brava, entendeu? [...] Então acaba sendo assim, mas o primeiro dia foi terrível, foi terrível... [itálicos nossos] (Professor Eduardo).
\end{abstract}

Em Ruis (2015) temos a defesa da ampliação dos estudos de gênero na Educação Infantil, como forma de enfrentamento e possibilidade de mudança de concepções no exercício da docência. Nas palavras de Ruis (2015, p. 73):

O trabalho docente consiste em outro ponto que merece destaque em estudos que procuram articular relações de gênero e educação. No caso da Educação Infantil, tais pesquisas são ainda mais pertinentes pelo fato de serem consideradas como um campo de trabalho feminino. Tal concepção resulta do processo de feminização do magistério, ocorrido no Brasil a partir do século $\mathrm{XX}[\ldots]$

O primeiro mês de trabalho, segundo o professor, foi o mais difícil, pois foi colocado à prova sobre sua competência e sobre sua sexualidade. Apesar de todas as descrenças em seu trabalho, Eduardo procurava não demonstrar insegurança e descontentamento sobre os comentários a ele dispensados. Na escola fez amizade com uma professora, que no momento assumia a função de coordenadora pedagógica, e era com ela que o professor desabafava e dela recebia conselhos e ajuda para enfrentar os desafios do início da carreira.

De acordo com o estudo realizado por Sayão (2005), os professores, quando iniciavam a carreira nas instituições voltadas ao atendimento da primeira infância, além de serem alvos de apostas de que não dariam certo naquele espaço, eram submetidos a uma porção de testes que abrangiam estratégias para perceber se dominavam o conhecimento para tratar com as crianças até o modo, o "jeito" de lidar com elas, bem como apreender as opções sexuais dos professores. Conforme a referida autora, "os primeiros momentos dos professores e sua chegada na Educação Infantil conformam uma espécie de Ritual de Passagem que demarca, muitas 
vezes, sua continuidade na profissão ou a busca por alternativas por meio da mudança do projeto profissional inicial” (SAYÃO, 2005, p. 65, destaques no original).

Com o professor pesquisado não foi diferente. O docente relata que em seu primeiro ano na Educação Infantil, além do desafio de se manter na profissão após a insistência de várias pessoas para que não assumisse o cargo, também teve que enfrentar outras dificuldades como a falta de uma sala de aula para trabalhar com a sua turma de alunos e alunas. Assim, no decorrer do primeiro ano foi obrigado a dar aulas em uma sala improvisada, a sala de informática, que ficava ao lado da sala da direção da escola.

O fato de estar na sala ao lado da sala da direção pode ser compreendido como uma forma de controle do seu trabalho, uma forma de vigiar o professor atuando, de intimidá-lo, uma vez que a diretora havia realizado algumas tentativas de impedir a sua entrada na profissão e estava disposta a fazê-lo desistir.

Essa situação de improvisos, de falta de sala, de espaço físico, se repetiu ao longo dos anos, sendo que somente no ano em que a pesquisa foi realizada é que o docente havia conseguido, de fato, uma sala de aula. Destarte, "a conquista do espaço profissional estava determinada por uma espécie de ritual mediante o qual muitas provas eram colocadas" (SAYÃO, 2005, p. 75).

Ao analisar a narrativa do professor sobre os seus primeiros anos atuando na instituição, percebemos que o mesmo foi constantemente colocado à prova. Por ser o primeiro homem a ingressar na profissão, foram muitas as curiosidades em torno de sua pessoa, de sua opção sexual, muitas as desconfianças sobre a sua competência e apostas em sua "inexperiência". Assim, a entrada do professor causou um estranhamento, era como se algo estivesse fora do lugar. Conforme Sayão (2005), uma explicação viável para todo esse estranhamento consiste na inadequação de uma figura masculina a um espaço que se estabeleceu como um reduto feminino. Dessa forma, por meio de uma soma de condutas coletivas, era necessário inserir este indivíduo numa determinada cultura da qual aparentemente se mostrava externo.

\section{Prática docente no contexto da Instituição de Educação Infantil}

Durante o período de observação, investigamos a prática diária do professor. Procuramos averiguar se ele conferia o comportamento, rendimento e o interesse das crianças como sendo inerentes aos gêneros. Ou seja, se possuía expectativas quanto aos modos de ser menina e de ser menino. 
O docente demonstrou que não seguia as práticas sexistas e dicotômicas que a maioria das professoras e profissionais da instituição da qual fazia parte costumavam adotar. Desse modo oferecia aos seus alunos e alunas diferentes possibilidades de organização e de vivências, independente dos gêneros.

Como forma de favorecer essa vivência entre os meninos e as meninas, o professor costumava organizar o espaço da sala de aula de diferentes maneiras e de acordo com a atividade a ser desenvolvida. A sala era cheia de carteiras e cadeiras que ocupavam quase todo o espaço, uma vez que no período contrário abrigava um grande número de crianças. $\mathrm{O}$ professor costumava variar a forma de ordenar o mobiliário, de modo que, às vezes, juntava as carteiras formando uma grande mesa onde todos/as se sentavam juntos, outras vezes formava duplas, formava semicírculos, etc. Essa organização diária da sala demandava esforço físico por parte do profissional, mas a preocupação em proporcionar às crianças um espaço mais amplo e adequado para a realização das atividades se sobressaía.

A análise da entrevista realizada com o professor, bem como a análise dos registros de observação, revela que o docente vivenciou momentos intensos de brincadeira durante a sua infância, o que contribuiu para um olhar sensível em sua prática cotidiana e para a sua capacidade de brincar junto com os seus alunos e alunas. Por várias vezes a pesquisadora presenciou cenas em que o professor corria, brincava de pega-pega, subia em árvores, junto dos meninos e meninas, sem qualquer distinção de gênero ou mesmo hierárquica. Nessas ocasiões, a alegria e o prazer eram visíveis em todos/as.

Percebemos um movimento do professor pesquisado em proporcionar aos seus alunos e alunas oportunidades de escolha e de experienciarem diferentes formas de ser menino e de ser menina, na contrapartida, muitas vezes, dos padrões estabelecidos e esperados socialmente para cada gênero.

\section{Considerações finais}

Por meio da análise da trajetória pessoal e profissional de um professor da pré-escola, buscamos registrar algumas das concepções a respeito da entrada de profissionais homens neste contexto educacional.

O docente pesquisado teve que enfrentar os mais diversos obstáculos no início de sua carreira, passando por inúmeras provações e "rituais" para se manter e ser aceito em um espaço predominantemente marcado pela presença feminina. 
O professor, aos poucos e por meio de estratégias por ele encontradas, conseguiu passar pelos rituais e seguiu na profissão, deixando de lado a imagem de um homem iniciante e sem experiência. Conquistou o seu espaço de atuação, enfrentou diversos desafios, conflitos e embates, e obteve o reconhecimento como professor, tanto pelas colegas de trabalho como pelas famílias.

Pudemos nos aproximar dessa etapa da educação por uma visão diferente da abordada pelos estudos acerca da feminização do magistério. A presença do docente nessa área corrobora para uma desnaturalização da ideia de Educação Infantil como profissão do gênero feminino e para a desconstrução do mito da mulher enquanto educadora nata e possuidora de dons naturais (ARCE, 1997, 2001).

Ao narrar os momentos iniciais na carreira docente, o professor apresentou algumas situações em que teve que se manter persistente na função, uma vez que as diferentes profissionais que atuavam na instituição, bem como os familiares das crianças, tinham uma visão naturalizada da pré-escola enquanto um espaço feminino.

Além disso, percebemos que o professor pode reforçar ou não as diferenças de gênero apresentadas por seus alunos e alunas. Por isso, acreditamos que essa investigação possa contribuir para que professores e professoras reflitam sobre suas práticas educativas com relação às questões de gênero, enxergando as crianças, ouvindo-as em suas necessidades, respeitando suas diferenças e preferências.

Portanto, a escola de Educação Infantil pode contribuir para a desconstrução dos estereótipos de gênero.

\section{REFERÊNCIAS}

ARCE, A. Jardineira, Tia e Professorinha: a realidade dos mitos. Dissertação (Mestrado em Educação) - Faculdade de Educação, Universidade Federal de Mato Grosso do Sul, Campo Grande, 1997.

ARCE, A. Documentação oficial e o mito da educadora nata na educação infantil. Cadernos de Pesquisa. 2001. Disponível em:

http://www.scielo.br/scielo.php?script=sci_arttext\&pid=S0100-

15742001000200009\&lng=pt\&nrm=isso. Acesso em: 03 fev. 2013.

BOGDAN, R. C.; BIKLEN, S. K. Investigação qualitativa em educação: uma introdução à teoria e aos métodos. Porto: Porto Editora, 1994.

CARVALHO, M. P. Entre a casa e a escola: educadoras de $1^{\circ}$ grau na periferia de São Paulo. Revista Brasileira de Estudos Pedagógicos, Brasília, v. 76, n. 184, p. 407-444, set./dez.,1995. Disponível em:

RIAEE - Revista Ibero-Americana de Estudos em Educação, Araraquara, v. 14, n. esp. 2, p. 1569-1579, jul., 2019. E-ISSN: 1982-5587. 
http://www.rbep.inep.gov.br/index.php/RBEP/article/viewFile/266/268. Acesso em: 3 fev. 2013.

CARVALHO, M. P. No coração da sala de aula: gênero e trabalho docente nas series iniciais. São Paulo: Xamã/Fapesp, 1998.

LOURO, G. L. Gênero, sexualidade e educação: uma perspectiva pós-estruturalista. Petrópolis: Vozes, 1997.

LÜDKE, M.; ANDRÉ, M. Pesquisa em educação: abordagens qualitativas. São Paulo: EPU, 1986.

MINAYO, M. C. S. (Org.). Pesquisa social: teoria, método e criatividade. Petrópolis, RJ: Vozes, 1994.

RUIS, F. F. Ser menino e menina, professor e professora na Educação Infantil: um entrelaçamento de vozes (Dissertação em Educação Sexual). Faculdade de Ciências e Letras, Universidade Estadual Paulista. Araraquara, 2015.

RUIS, F. F.; PEREZ, M. C. A. Ouvindo meninos: relações de gênero na educação infantil. DOXA: Revista Brasileira de Psicologia e Educação, p. 283-294, jun., 2017. ISSN 25948385. Disponível em: https://periodicos.fclar.unesp.br/doxa/article/view/10922/7073. Acesso em: 31 jan. 2019.

SARMENTO, T. Correr o risco: ser homem numa profissão "naturalmente" feminina. In: Congresso Português de sociologia: sociedades contemporâneas: reflexividade e ação, 5, 2002, Braga. Anais [...] Braga, Portugal: [s.n.].

SAYÃO, D. T. Relações de gênero e trabalho docente na educação infantil: um estudo de professores em creche. Tese (Doutorado em Educação) - Centro de Ciências da Educação, Universidade Federal de Santa Catarina, Florianópolis, 2005.

\section{Como referenciar este artigo}

SCIOTTI, Fernanda Ferrari Ruis; PEREZ, Marcia Cristina Argenti; BELLIDO, Luciana Ponce. Ser professor na educação infantil: gênero e docência. Revista Ibero-Americana de Estudos em Educação, Araraquara, v. 14, n. esp. 2, p. 1569-1579, jul., 2019. E-ISSN: 1982-5587. DOI: 10.21723/riaee.v14iesp.2.12616

Submetido em: 30/09/2018

Revisões requeridas: 25/02/2019

Aprovado em: 29/04/2019

Publicado em: 26/06/2019 